\title{
PEMIKIRAN PENDIDIKAN MUHAMMAD NAQUIB AL-ATTAS
}

\author{
Zulham Effendi \\ Program Studi Pendidikan Bahasa Arab STAI As-Sunnah Deli Serdang \\ Jl. Medan-Tg. Morawa, Km. 13 G. Darmo, Desa B. Sari, Kec. Tg. Morawa Kab. Deli Serdang \\ zlhm.eff@gmail.com
}

\begin{abstract}
Abstrak: Muhammad Naquib al-Attas dilahirkan di Bogor, Jawa Barat, pada 5 September 1931. Ibunya asli Bogor, Indonesia dan ayahnya masih tergolong bangsawan di Johor, Malaysia. Konsep pendidikan Islam dalam pandangan Naquib al-Attas lebih cenderung menggunakan istilah ta'dib yang artinya mengajarkan adab atau mendidik, daripada istilah-istilah lainnya. Naquib al-Attas melihat bahwa adab merupakan salah satu misi utama yang dibawa Rasulullah yang bersinggungan dengan umatnya. Dengan menggunakan term adab tersebut, berarti menghidupkan Sunnah Rasul. Naquib Al-Attas beranggapan bahwa tujuan pendidikan Islam adalah menanamkan kebajikan dalam "diri manusia" sebagai manusia dan sebagai diri individu. Tujuan akhir pendidikan Islam adalah menghasilkan manusia yang baik, yakni kehidupan materiil dan spiritualnya. Bagi Al-Attas, sistem pendidikan dibagi dalam tiga tahapan, yaitu rendah, menengah dan tinggi. Dan kurikulum pendidikan Islam harus ada di dalam kandungannya dua aspek, yaitu Ilmu fardlu 'ain dan Ilmu fardlu kifayah.
\end{abstract}

Kata Kunci: Pemikiran, Pendidikan, Al-Attas

\section{Pendahuluan}

Pendidikan merupakan perkara yang sangat penting dalam kehidupan manusia. Pendidikan, terutama pendidikan Islam dengan berbagai coraknya berorientasi memberikan bekal kepada manusia (peserta didik) untuk mencapai kebahagiaan dunia dan akhirat. Oleh karena itu, semestinya pendidikan Islam selalu diperbaharui konsep dan aktualisasinya dalam rangka merespon perkembangan zaman yang selalu dinamis dan temporal, agar peserta didik dalam pendidikan Islam tidak hanya berorientasi pada kebahagiaan hidup setelah mati tetapi kebahagiaan hidup di dunia juga bisa diraih.

Muhammad Naquib Al-Attas, termasuk salah satu pemikir dan pembaharu pendidikan Islam dengan ide-ide segarnya. Al-Attas tidak hanya sebagai intelektual yang concern kepada pendidikan dan persoalan umum umat Islam, tetapi juga pakar dalam berbagai bidang ilmu pengetahuan. Ia juga dianggap sebagai tokoh penggagas Islamisasi ilmu pengetahuan yang mempengaruhi banyak tokoh lainnya. Ia secara sistematis merumuskan strategi Islamisasi ilmu dalam bentuk kurikulum pendidikan untuk umat Islam. Meski demikian, ide-ide 
Al-Attas tentang Islamisasi ilmu pengetahuan dalam pendidikan Islam banyak memperoleh tantangan dari para pemikir yang terlahir dari dunia Barat.

Terlepas dari itu, Al-Attas telah dikenal sebagai pemikir pendidikan Islam yang sampai saat ini kesohor di kalangan umat Islam dunia dan juga sebagai figur pembaharu pendidikan Islam. Respon positif ataupun negatif dari para intelektual yang ditujukan kepada Al-Attas menjadikan kajian terhadap pemikiran Al-Attas semakin menarik.

Pada tulisan ini, penulis akan menguak sebagian dari pemikiran pendidikan Muhammad Naquib al-Attas, di antaranya riwayat hidup Muhammad Naquib al-Attas, karya-karya ilmiahnya dan pemikirannnya mengenai pendidikan Islam.

\section{Pembahasan}

\section{A. Riwayat Hidup Muhammad Naquib al-Attas}

Muhammad Naquib al-Attas dilahirkan di Bogor, Jawa Barat, pada 5 September 1931. Ibunya yang asli Bogor masih keturunan bangsawan Sunda. Sedangkan ayahnya masih tergolong bangsawan di Johor.

Bimbingan orang tua selama lima tahun pertama merupakan penanaman sifat dasar bagi kelanjutan hidupnya. Orangtuanya yang sangat religius memberikan pendidikan dasar Islam yang kuat.

Ketika berusia 5 tahun, al-Attas diajak orangtuanya migrasi ke Malaysia. Di sini al-Attas dimasukkan dalam pendidikan dasar Ngee Heng Primary School sampai usia 10 tahun. Melihat perkembangan yang kurang menguntungkan, yakni ketika Jepang menguasai Malaysia, maka al-Attas dan keluarganya pindah ke Indonesia. Di sini, ia kemudian melanjutkan studinya di sekolah Urwah al-Wusqa, Sukabumi selama lima tahun. Di tempat ini, al-Attas mulai mendalami dan mendapatkan pemahaman tradisi Islam yang kuat, terutama tarekat. Hal ini dapat dimengerti karena saat itu, di Sukabumi telah berkembang perkumpulan Tarekat Naqsabandiyah.

Karena terdorong oleh panggilan batinnya untuk mengamalkan ilmunya yang diperoleh di Sukabumi, sekembalinya di Malaysia, al-Attas memasuki dunia militer dengan mendaftarkan diri sebagai tentara kerajaan dalam upaya mengusir 
penjajah Jepang. Dalam bidang kemiliteran ini, al-Attas telah menunjukkan kecerdasannya, sehingga atasannya memilih dia sebagai salah satu peserta pendidikan militer yang lebih tinggi. Dia belajar berbagai sekolah militer di Inggris. Bahkan dia sempat mengenyam pengalaman yang merupakan salah satu akademi militer yang cukup bergengsi di Inggris.

Sesudah Malaysia merdeka, pada tahun 1957, al-Attas mengundurkan diri dari dinas militer dan mengembangkan potensi dasarnya di bidang intelektual. Untuk itu, al-Attas sempat kuliah di Universitas Malaya selama dua tahun. Berkat kecerdesannya dan kesungguhannnya dalam belajar, ia kemudian dikirim oleh pemerintah Malaysia untuk melanjutkan studi di Institute of Islamic Studies, McGill University, Kanada. Dalam waktu yang relatif singkat, ia pada tahun 1962 berhasil meraih gelar master dengan mempertahankan tesis berjudul Raniry and Wujudiyah of 17 Century Aceh. Dia sangat tertarik pada praktik sufi yang berkembang di Indonesia dan Malaysia, sehingga cukup wajar bila tesis yang diangkat adalah konsep Wujudiyah al-Raniey. Melalui tesis ini ia ingin membuktikan bahwa Islamisasi yang berkembang di kawasan tersebut bukan dilaksanakan oleh Kolonial Belanda, melainkan murni oleh upaya umat Islam sendiri. ${ }^{1}$

Dalam rangka memperdalam dan memperluas wawasan intelektualnya, alAttas kemudian melanjutkan studi ke School of Oriental and African Studies di Universitas London. Di sinilah dia bertemu dengan Lings, seorang professor asal Inggris yang memiliki pengaruh besar dalam diri al-Attas, walaupun itu hanya terbatas pada dataran metodologis. Selama lebih kurang dua tahun (1963-1965), dengan bimbingan Martin Lings, al-Attas menyelesaikan studinya dengan mempertahankan disertasinya yang berjudul "The Mysticisme of Hamzah Pansuri. ",2

Dalam bidang karier atau pekerjaan, al-Attas memulai dengan jabatan di Jurusan Kajian Melayu pada Universitas Malaya. Tugas ini ia laksanakan pada

\footnotetext{
1 Abuddin Nata, Pemikiran Pendidikan Islam dan Barat, (Cet.II. Jakarta: PT Raja Grafindo Persada, 2013), hlm. 331-332.

2 Muhammad Naquib al-Attas, Prolego Mena to The Metaphysics of Islam, (Kuala Lumpur: ISTAC, 2001), hlm. 252-283.
} 
tahun 1966 hingga tahun 1970. Pada lembaga ini ia menekankan tentang pentingnya kajian Melayu.

Selanjutnya pada tahun 1977, al-Attas menyampaikan sebuah makalah yang berjudul Priliminary Thought on the Nature of Knowledge and the Definition and Aims of Education di hadapan peserta konperensi Dunia Islam pertama tentang pendidikan Islam di Makkah al-Mukarramah. Dengan orasi yang meyakinkan banyak peserta yang memberikan respon positif. Salah satu respon tersebut adalah diterimanya ide tersebut oleh Organisasi Konperensi Islam. Selanjutnya sebagai realisasi dari ide-ide cemerlang al-Attas, OKI memberi kepercayaan untuk mendirikan sebuah Universitas Internasional di Malaysia pada tahun $1984 .^{3}$

Di berbagai badan ilmiah internasional, Al-Attas juga diangkat sebagai anggota, antara lain: Member of International Congress of Medieval Philosophy, Member of International Congress of The VII Centenary of st. Thomas Aquinas, member of International Congress of the VII Centenary of st. Bonaventura da Bognoregio, Member Malaysian Delegate International congress on the Millinary of Al-Biruni juga Principal Consultant world of Islam Festival Congress, Sectional Chairman for Education world of Islamic Festival Congress. Al-Attas juga termasuk dalam daftar nama-nama orang terkenal di dunia dalam Marquis Who's Who in the World 1974/1975 dan 1976/1977. Ia dikenal juga sebagai penyair dan seniman dalam bidang seni kaligrafi dan pahat. Juga sangat mahir dalam beberapa bahasa seperti bahasa Inggris, Arab, Latin, Jerman, Spanyol dan bahasa Melayu. ${ }^{4}$

Pada tanggal 22 Nopember 1988 menteri pendidikan Malaysia yang juga presiden Universitas Islam Antara bangsa (saat itu Anwar Ibrahim) melantik AlAttas sebagai profesor dalam bidang pemikiran dan tamaddun Islam merangkap rektor di International Institute of Islamic Thought and Civilization (Institut Antara bangsa Pemikiran dan tamaddun Islam). ${ }^{5}$

\footnotetext{
${ }^{3}$ Abuddin Nata, Pemikiran Pendidikan Islam dan Barat, hlm. 334.

${ }^{4}$ Ismail SM. Paradigma Pendidikan Islam, Prof. Dr. Syed Naquib al-Attas, dalam Abdul Kholiq, dkk., Pemikiran Pendidikan Islam, kajian Tokoh Klasik dan Kontemporer, (Yogyakarta: Pustaka Pelajar, 1999), hlm. 273.

${ }^{5}$ Muhammad Naquib Al-Attas, Islam dalam sejarah dan Kebudayaan Melayu, (Bandung: Mizan, 1990), hlm. 10-11.
} 
Dari sini dapat dilihat, Al Attas adalah intelektual kontemporer yang pemikirannya menjadi titik pencerahan bagi pengembangan Islam dalam menghadapi arus globalisasi.

\section{B. Karya-karya Muhammad Naquib al-Attas}

Untuk mengenali karya Muhammad Naquib al-Attas, kita dapat melihat dari dua bagian, yakni karya-karya kesarjanaan (scholarly writing), dan karya-karya pemikiran. Yang pertama lebih menggambarkan dia sebagai seorang ahli atau sarjana (scholar). Ini terutama dapat dilihat dalam karya-karyanya yang berkaitan dengan kebudayaan Melayu dan Nusantara, khususnya mengenai mistisisme. Sementara yang kedua menggambarkan dia sebagai pemikir. Berikut ini karyakarya yang berkaitan dengan bagian pertama:

1. Rangkaian Rubui'iyat, Dewan Bahasa \& Pustaka, Kuala Lumpur, 1959.

2. Some Aspect of Sufism as Understood and Practiced among the Malays, MSRI, Singapore, 1963.

3. Raniri and the Wujudiyah of $17^{\text {th }}$ Century Acheh, Mograph of the Royal Asitic Society, Malaysian Branch, No. 111, Singapore, 1966.

4. The Origin of the Malay Sha ir, Dewan Bahasa \& Pustaka, Kuala Lumpur,1968.

5. Preleminary Statement on a General Theory of the Islamization of the Malay-Indonesia Archipelago, Dewan Bahasa \& Pustaka, Kuala Lumpur, 1969.

6. The Mysticism of Hamzah Fansuri, Universitas Malaya Press, Kuala Lumpur, 1969.

7. Conluding Postcrip to the Malay Sha ir, Dewan Bahasa \& Pustaka, Kuala Lumpur, 1971.

Sedangkan karya yang berkenaan dengan gagasan/pemikiran banyak berbicara tentang konsep, terutama konsep pendidikan, filsafat dan islamisasi ilmu. Berikut ini karya-karya yang masuk bagian kedua:

1. Islam: The Concept of Religion and the Foundation of Ethic and Morality, ABIM, Kuala Lumpur, 1976.

2. Preliminary Thought on the Nature of Knowledge and the Definition and Aims of Education, PMIM, Kuala Lumpur, 1977. 
3. Islam and Secularism, ABIM, Kuala Lumpur, 1978.

4. Islam, Secularism, and Philosophy of the Nature, 1985.

5. Dilema Kaum Muslimin, Bina ILmu, Surabaya, tt.

6. The Concept of Education in Islam:A framework for a Islamic Philosophy of Education, ABIM, Kuala Lumpur, 1980.

7. Aims and Objectives of Islamic Education, Hodder-Stoughton, London and University of King Abdul Aziz, Jeddah, 1979.

8. Islam and the Filsafat Sain, Penerjemah: Saiful Muzani, Mizan, Bandung, $1995 .^{6}$

Melalui dua macam karya di atas, al-Attas terlihat jelas dalam programprogram kerja jangka panjang Institut Pemikiran dan Tamaddun Islam yang dipimpinnya, yaitu suatu bentuk pelembagaan dari obsesi dan cita-cita intelektualnya.

\section{Pemikiran Pendidikan Muhammad Naquib al-Attas}

\section{Konsep Pendidikan Islam}

Ada beberapa istilah yang dipakai untuk menunjuk pengertian "pendidikan Islam" yang pengistilahan itu diambil dari lafad bahasa Arab (al-Qur'an) maupun al-sunnah. Misalnya dijumpai kata tarbiyah, ta'lim, dan ta'dib bahkan ada yang disebut riyadlah. Namun dalam pembahasan berikut ini akan disajikan konsep pendidikan Islam versi Naquib al-Attas.

Pemaparan konsep pendidikan Islam dalam pandangan Naquib al-Attas lebih cenderung menggunakan istilah (lafad) ta'dib, daripada istilah-istilah lainnya. Pemilihan istilah $t a$ 'dib, merupakan hasil analisa tersendiri bagi al-Attas dengan menganalisis dari sisi semantik dan kandungan yang disesuaikan dengan pesanpesan moralnya.

Sekalipun istilah tarbiyah dan ta'lim telah mengakar dan mempopuler, ia menempatkan ta'dib sebagai sebuah konsep yang dianggap lebih sesuai dengan konsep pendidikan Islam. ${ }^{7}$

\footnotetext{
${ }^{6}$ Wan Mohd Nor Wan Daud, Filsafat dan Praktek Pendidikan Islam Syed Naquib AlAttas,(Bandung: Mizan, 2003), hlm. 56-57.

${ }^{7}$ Ismail SM. dalam Abdul Kholiq, dkk., hlm. 275.
} 
Dalam penjelasan Mahmud Yunus dalam kamusnya, kata ta'dib sebagaimana yang menjadi pilihan al-Attas, merupakan kata (kalimat) yang berasal dari kata أَدَّبَ (addaba) yang berarti memberi adab, atau mendidik. ${ }^{8}$

Dalam pandangan Naquib al-Attas, dengan menggunakan term di atas, dapat dipahami bahwa pendidikan Islam adalah proses internalisasi dan penanaman adab pada diri manusia. Sehingga muatan substansial yang terjadi dalam kegiatan pendidikan Islam adalah interaksi yang menanamkan adab. Seperti yang diungkapkan Naquib al-Attas, bahwa pengajaran dan proses mempelajari ketrampilan betapa pun ilmiahnya tidak dapat diartikan sebagai pendidikan bilamana di dalamnya tidak ditanamkan 'sesuatu'.?

Naquib al-Attas melihat bahwa adab merupakan salah satu misi utama yang dibawa Rasulullah yang bersinggungan dengan umatnya. Dengan menggunakan term adab tersebut, berarti menghidupkan Sunnah Rasul. Konseptualisasinya adalah sebagaimana sabdanya:

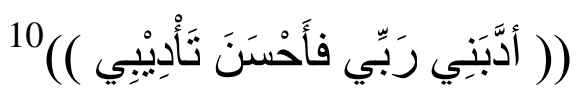

"Tuhanku telah mendidikku (addaba), dengan demikian membuat pendidikanku (ta'dib) yang paling baik".

Sesuai dengan ungkapan hadits di atas, bahwa pendidikan merupakan pilar utama untuk menanamkan adab pada diri manusia, agar berhasil dalam hidupnya, baik di dunia ini maupun di akhirat kemudian. Karena itu, pendidikan Islam dimaksudkan sebagai sebuah wahana penting untuk penanaman ilmu pengetahuan yang memiliki kegunaan pragmatis dengan kehidupan masyarakat. Karena itu, menurut Naquib al-Attas, antara ilmu, amal dan adab merupakan satu kesatuan (entitas) yang utuh. Kecenderungan memilih term ini, bagi Naquib al-Attas bahwa pendidikan tidak hanya berbicara yang teoritis, melainkan memiliki relevansi secara langsung dengan aktivitas di mana manusia hidup. Jadi, antara ilmu dan amal harus berjalan seiring dan seirama. ${ }^{11}$

\footnotetext{
${ }^{8}$ Mahmud Yunus, Kamus Arab-Indonesi, (Jakarta: PT. Hidakarya Agung, 1990), hlm. 37.

${ }^{9}$ Ismail SM. dalam Abdul Kholiq, dkk., hlm. 275.

${ }^{10}$ Hadis ini dhoif, bahkan tidak ada asal atau sanadnya sebagaimana yang dijelaskan Ibnu Taimiyah, al-Sakhawi, Ibn al-Jauzi dan ulama hadis lainnya. Lihat Faidhu al-Qadir karya Abdurrauf al-Munawi dan Kanzu al-Ummal karya Ali al-Muttaqi al-Hindi.

11 Syed Naquib al-Attas, Konsep Pendidikan Dalam Islam, Suatu Pembinaan Filsafat Pendidikan Islam, terj. Haidar Baqir, (Cet. IV. Bandung:Mizan, 1994), hlm. 222.
} 
Naquib al-Attas membantah istilah tarbiyah, sebagaimana yang digunakan oleh beberapa pakar pedagogis dalam konsep pendidikan Islam. Ia berpandangan bahwa term tarbiyah relatif baru dan pada hakikatnya tercermin dari Barat. Bagi Naquib al-Attas konsep itu masih bersifat generik, yang berarti semua makhluk hidup, bahkan tumbuhan pun ikut terkafer di dalamnya. Dengan demikian, kata tarbiyah mengandung unsur pendidikan yang bersifat fisik dan material.

Lebih lanjut, al-Attas menjelaskan bahwa perbedaan antara ta'dib dan tarbiyah adalah terletak pada makna substansinya. Kalau tarbiyah lebih menonjolkan pada aspek kasih sayang (rahmah), sementara ta'dib, selain dimensi rahmah juga bertitik tolak pada aspek ilmu pengetahuan. Secara mendasar, ia mengakui bahwa dengan konsep ta'dib, pendidikan Islam berarti mencakup seluruh unsur-unsur pengetahuan, pengajaran, dan pengasuhan yang baik. Karena itu, di luar istilah $t a^{\prime} d i b$, bagi al-Attas tidak perlu pakai.

Sebuah pemaknaan dari konsep ta'dib ini, al-Attas beranggapan bahwa diri manusia adalah sabyek yang dapat didik, disadarkan sesuai dengan posisinya sebagai makhluk kosmis. Penekanan pada segi adab dimaksudkan agar ilmu yang diperoleh dapat diamalkan secara baik dan tidak disalahgunakan menurut kehendak bebas pemilik ilmu, sebab ilmu tidak bebas nilai (value free) tetapi sarat nilai (value laden), yakni nilai-nilai Islam yang mengharuskan pelakunya untuk mengamalkan demi kepentingan dan kemaslahatan umat manusia. ${ }^{12}$

\section{Tujuan Pendidikan Islam}

Naquib Al-Attas beranggapan bahwa tujuan pendidikan Islam adalah menanamkan kebajikan dalam "diri manusia" sebagai manusia dan sebagai diri individu. Tujuan akhir pendidikan Islam adalah menghasilkan manusia yang baik, yakni kehidupan materiil dan spiritualnya. Di samping, tujuan pendidikan Islam yang menitik beratkan pada pembentukan aspek pribadi individu, juga mengharapkan pembentukan masyarakat yang idel tidak terabaikan. Seperti dalam ucapannya, "...karena masyarakat terdiri dari perseorangan-perseorangan maka membuat setiap orang atau sebagian besar diantaranya menjadi orang-orang baik berarti pula menghasilkan suatu masyarakat yang baik. "13

\footnotetext{
${ }^{12}$ Ibid., hlm. 64-66.

${ }^{13}$ Ibid., hlm. 23.
} 
Secara ideal, Naquib al-Attas menghendaki pendidikan Islam mampu mencetak manusia yang baik secara universal (al-insan al-kamil). Suatu tujuan yang mengarah pada dua demensi sekaligus yakni, sebagai Abdullah (hamba Allah), dan sebagai Khalifah fi al-Ardl (wakil Allah di muka bumi). Karena itu, sistem pendidikan Islam harus merefleksikan ilmu pengetahuan dan perilaku Rasulullah shallallahu 'alaihi wa sallam, serta berkewajiban mewujudkan umat Muslim yang menampilkan kualitas keteladanan Nabi shallallahu 'alaihi wa sallam.

Dengan harapan yang tinggi, Naquib al-Attas menginginkan agar pendidikan Islam dapat mencetak manusia paripurna, insan kamil yang bercirikan universalis dalam wawasan dan ilmu pengetahuan dengan bercermin kepada ketauladanan Nabi shallallahu 'alaihi wa sallam. Pandangan al-Attas tentang masyarakat yang baik, sesungguhnya tidak terlepas dari individu-individu yang baik. Jadi, salah satu upaya untuk mewujudkan masyarakat yang baik, berarti tugas pendidikan harus membentuk kepribadian masing-masing individu secara baik. Karena masyarakat kumpulan dari individu-individu. ${ }^{14}$

\section{Sistem Pendidikan Islam}

Sebagaimana yang tertuang dalam tujuan pendidikan Islam di atas, bahwa Naquib al-Attas mendeskripsikan tujuan tersebut adalah mewujudkan manusia sempurna secara universal. Dengan begitu, berarti sistem pendidikan Islam harus memahami seperangkat bagian-bagian yang terkait satu sama lain dalam sistem pendidikan.

Naquib al-Attas berpandangan bahwa manusia terdiri dari dua unsur, jasmani dan ruhani, maka ilmu juga terbagi dua katagori, yaitu ilmu pemberian Allah (melalui wahyu ilahi), dan ilmu capaian (yang diperoleh melalui usaha pengamatan, pengalaman dan riset manusia)

Al-Attas membuat skema yang menjelaskan kedudukan manusia sekaligus pengetahuan. Bahwa pada dasarnya ilmu pengetahuan menurut dia, adalah berian Allah (God Given) dengan mengacu pada fakultas dan indra ruhaniayah manusia. Sedangkan ilmu capaian mengacu pada tingkatan dan indra jasmaniyah.

\footnotetext{
${ }^{14}$ Ibid., hlm. 23-24.
} 
Menurut Naquib al-Attas, bahwa akal merupakan mata rantai yang menghubungkan antara yang jasmani dan yang ruhani, karena akal pada hakikatnya adalah substansi ruhaniyah yang menjadikan manusia bisa memahami hakikat dan kebenaran ruhaniyah. Dengan kata lain, dia mengatakan bahwa ilmuilmu agama merupakan kewajiban individu yang menjadi pusat jantung diri manusia. $^{15}$

Bagi Al-Attas, sistem pendidikan dibagi dalam tiga tahapan, yaitu rendah, menengah dan tinggi. Dan ilmu dikategorikan menjadi dua, yaitu Ilmu fardlu 'ain dan Ilmu fardlu kifayah. Ilmu fardlu 'ain diajarkan tidak hanya pada tingkat primer (rendah) melainkan juga pada tingkat sekunder (menengah) pra-universitas dan juga tingkat universitas. ${ }^{16}$ Pengetahuan inti pada tingkat universitas, di dasarkan pada beberapa konsep unsur esensial yaitu Manusia (insan), sifat agama (din) dan keterlibatan manusia di dalamnya, pengetahuan ('ilmu dan ma'rifah), kearifan (hikmah) dan keadilan ('adl) mengenai manusia dan agamanya, sifat perbuatan yang benar ('amal-adab). Dan Konsep Universitas (kuliiyah-jami'ah). ${ }^{17}$

\section{Kurikulum Pendidikan Islam}

Bangunan kurikulum pendidikan Islam, menurut al-Attas, berangkat dari pandangan bahwa karena manusia itu bersifat dualistik, kandungan kurikulum pendidikan harus memenuhi dua aspek dasar manusia tersebut. Pertama, memenuhi kebutuhannya yang berdimensi permanen dan spiritual atau fardhu 'ain; dan kedua, yang memenuhi kebutuhan material-emosional atau fardhu kifayah. Pemahaman dan pelaksanaan yang tepat terhadap kategori ilmu pengetahuan fardhu 'ain (kewajiban bagi diri) dan fardhu kifayah (kewajiban bagi masyarakat) ini akan memastikan realisasi kesejahteraan individu dan sosial. Walaupun kategori pengetahuan yang kedua (fardhu kifayah) berkaitan langsung dengan masyarakat, peranan pengetahuan pertama (fardhu 'ain) akan mempunyai pengaruh signifikan secara tidak langsung. Dimensi pertama di atas dijadikan nilai-nilai dasar (core values) bagi pengembangan dimensi selanjutnya, yang meliputi aspek keilmuan, aspek life skill dan aspek-aspek lainnya. Jika aspek

\footnotetext{
${ }^{15}$ Ibid., hlm. 40-41.

${ }^{16}$ Ismail SM. dalam Abdul Kholiq, dkk., hlm. 88.

${ }^{17}$ Syed Naquib al-Attas, Konsep Pendidikan Dalam Islam, hlm. 238-239.
} 
keilmuan dikembangkan dengan berlandaskan pada aspek keilmuan pertama, maka ilmu pengetahuan di sini menjadi media memahami dan menghayati Tuhan dalam bentuk kelakuan empirik ketundukan kepada segala peraturan Allah. ${ }^{18}$

Nilai-nilai dasar (core values) akan memberikan makna terhadap suatu proses sebagai pengabdian kepada Tuhan. Sebab dalam Islam sendiri tidak mengena dikotomi ilmu pengetahuan, karena itu, semua disiplin ilmu bisa didekati dengan nuansa "ilahiyah" dalam mengantarkan manusia dan peradabannya menuju kesejahteraan dunia dan akhirat. Dalam merumuskan konsep kurikulum, norma agama perlu dijadikan dasar dalam menafsirkan semua pengetahuan modern dari sudut pandang Islam. ${ }^{19}$

Kandungan terperinci dari dua kategori ilmu pengetahuan yang telah disebutkan, yaitu ilmu fardhu 'ain (kewajiban bagi diri) dan ilmu fardhu kifayah (kewajiban bagi masyarakat) adalah sebagai berikut:

\section{Fardu Ain (Ilmu-ilmu agama)}

1. Kitab Suci Al-Qur'an: pembacaan dan interpretasinya (tafsir dan ta'wil).

2. Sunnah: kehidupan Nabi; sejarah dan risalah nabi-nabi terdahulu, hadis dan perawinya.

3. Syari'at: fiqih dan hukum; prinsip-prinsip dan pengamalan Islam (Islam, Iman, Ihsan).

4. Teologi (ilmu Kalam); Tuhan, Zat-Nya, Sifat-Sifat, Nama-Nama, dan perbuatan-Nya (al-tauhid).

5. Metafisika Islam (at-Tasawwuf-irfan); psikologi, kosmologi dan ontologi; elemen-elemen dalam filsafat Islam (termasuk doktrin-doktrin kosmologis yang benar, berkenaan dengan tingkatan-tingkatan wujud).

6. Ilmu-ilmu bahasa (linguistik); bahasa Arab, tata bahasa, leksikografi dan sastra.

\section{Fardu Kifayah}

18 Usman Abu Bakar dan Surahim, Fungsi Ganda Lembaga Pendidikan Islam, (Yogyakarta: Safiria Insania, 2005), hlm. 139.

${ }^{19}$ Abdurrahmansyah, Wacana Pendidikan Islam (Khazanah Filosofis dan Implementasi Kurikulum, Metodologi dan Tantangan Pendidikan Moralitas), (Yogyakarta: Global Pustaka Utama, 2005 ), hlm. 183. 
Pengetahuan fardu kifayah tidak diwajibkan kepada setiap muslim untuk mempelajarinya, tetapi seluruh masyarakat muslim harus bertanggung jawab kalau tidak ada seorang pun yang mempelajarinya. Bagaimanapun juga ilmu ini penting untuk memberikan landasan teoritis dan motivasi keagamaan kepada umat Islam untuk mempelajari dan mengembangkan segala ilmu pengetahuan ataupun Teknologi yang diperlukan untuk kemakmuran masyarakat.

Dalam hal ini Al-Attas membagi pengetahuan fardu kifayah menjadi delapan disiplin ilmu, yaitu:

1. Ilmu-ilmu Kemanusiaan.

2. Ilmu-ilmu Alam.

3. Ilmu-ilmu Terapan.

4. Ilmu-ilmu Teknologi.

5. Perbandingan Agama.

6. Kebudayaan dan peradaban Barat.

7. Ilmu-ilmu Linguistik: bahasa-bahasa Islam, dan

8. Sejarah Islam. ${ }^{20}$

Walaupun begitu Al Attas tidak membatasi pengetahuan fardu kifayah hanya delapan disiplin ilmu saja, tetapi tidak terbatas. Karena pada prinsipnya pengetahuan (ilm) itu sendiri adalah sifat Tuhan.

Menurut Al Attas, Struktur ilmu pengetahuan dan kurikulum Pendidikan Islam itu harus mampu menggambarkan manusia dan hakekatnya. Adanya pembedaan keilmuan ini bukan untuk mendikotomikan Ilmu Pengetahuan tetapi itu menjadi satu kesatuan yang dinamis untuk membebaskan manusia dan menumbuhkan potensi manusia. Kebebasan dalam akademik menurut Al Attas bukanlah kebebasan tanpa batas tapi kebebasan akademik dimaknai sebagai dasar pencapaian dan penyebarluasan adab setinggi-tingginya sesuai kemampuan. ${ }^{21}$

\section{Penutup}

Muhammad Naquib al-Attas dilahirkan di Bogor, Jawa Barat, pada 5 September 1931. Ibunya yang asli Bogor masih keturunan bangsawan Sunda. Sedangkan ayahnya masih tergolong bangsawan di Johor, Malaysia.

\footnotetext{
${ }^{20}$ Wan Mohd Nor Wan Daud, Filsafat dan Praktek Pendidikan....., hlm. 274-282.

${ }^{21}$ Ibid., hlm. 237.
} 
Naquib al-Attas memiliki banyak karya ilmiah, diantara karya-karyanya ialah Rangkaian Rubui'iyat, Some Aspect of Sufism as Understood and Practiced among the Malays, Raniri and the Wujudiyah of $17^{\text {th }}$ Century Acheh, Mograph of the Royal Asitic Society, The Origin of the Malay Sha ir Preleminary Statement on a General Theory of the Islamization of the Malay-Indonesia Archipelago, The Mysticism of Hamzah Fansuri, Conluding Postcrip to the Malay Sha`ir, Islam: The Concept of Religion and the Foundation of Ethic and Morality, Preliminary Thought on the Nature of Knowledge and the Definition and Aims of Education, Islam and Secularism, Islam, Secularism, and Philosophy of the Nature, Dilema Kaum Muslimin, The Concept of Education in Islam: A framework for a Islamic Philosophy of Education, Aims and Objectives of Islamic Education, HodderStoughtonIslam and the Filsafat Sain.

Pemaparan konsep pendidikan Islam dalam pandangan Naquib al-Attas lebih cenderung menggunakan istilah (lafad) ta'dib yang artinya mengajarkan adab atau mendidik, daripada istilah-istilah lainnya. Naquib al-Attas melihat bahwa adab merupakan salah satu misi utama yang dibawa Rasulullah yang bersinggungan dengan umatnya. Dengan menggunakan term adab tersebut, berarti menghidupkan Sunnah Rasul.

Naquib Al-Attas beranggapan bahwa tujuan pendidikan Islam adalah menanamkan kebajikan dalam "diri manusia" sebagai manusia dan sebagai diri individu. Tujuan akhir pendidikan Islam adalah menghasilkan manusia yang baik, yakni kehidupan materiil dan spiritualnya.

Bagi Al-Attas, sistem pendidikan dibagi dalam tiga tahapan, yaitu rendah, menengah dan tinggi.

Dan kurikulum pendidikan Islam harus ada di dalam kandungannya dua aspek, yaitu Ilmu fardlu 'ain dan Ilmu fardlu kifayah. 


\section{Pustaka Acuan}

Abdurrahmansyah, Wacana Pendidikan Islam (Khazanah Filosofis dan Implementasi Kurikulum, Metodologi dan Tantangan Pendidikan Moralitas). Yogyakarta: Global Pustaka Utama, 2005.

Abu Bakar, Usman dan Surahim, Fungsi Ganda Lembaga Pendidikan Islam. Yogyakarta: Safiria Insania, 2005.

Attas, Muhammad Naquib al, Islam dalam sejarah dan Kebudayaan Melayu. Bandung: Mizan, 1990.

Lumpur: ISTAC, 2001.

Prolego Mena to The Metaphysics of Islam. Kuala , Konsep Pendidikan Dalam Islam, Suatu Pembinaan Filsafat Pendidikan Islam, terj. Haidar Baqir. Cet. IV. Bandung:Mizan, 1994.

Hindi, Ali ibn Hisamuddin al-Muttaqi al, Kanzu al-Ummal Fi Sunan al-Aqwal wa al-Af'al. Bairut: Muassasah al-Risalah, 1989.

Ismail SM. Paradigma Pendidikan Islam, Prof. Dr. Syed Naquib al-Attas, dalam Abdul Kholiq, dkk., Pemikiran Pendidikan Islam, kajian Tokoh Klasik dan Kontemporer. Yogyakarta: Pustaka Pelajar, 1999..

Munawi, Abdurrauf al, Faidl al-Qadir Syarh al-Jami' al-Shaghir. Cet. I. Mesir: al-Maktabah al-Tijariyah al-Kubra, $1356 \mathrm{M}$.

Nata, Abuddin, Pemikiran Pendidikan Islam dan Barat. Cet.II. Jakarta: PT Raja Grafindo Persada, 2013.

Wan Mohd Nor Wan Daud, Filsafat dan Praktek Pendidikan Islam Syed Naquib Al-Attas. Bandung: Mizan, 2003.

Yunus, Mahmud, Kamus Arab-Indonesi. Jakarta: PT. Hidakarya Agung, 1990. 